\title{
Genetic relationships among Pasteurella trehalosi isolates based on multilocus enzyme electrophoresis
}

\author{
Robert L. Davies, ${ }^{1}$ Scott Arkinsaw ${ }^{1}$ and Robert K. Selander ${ }^{2}$ \\ Author for correspondence: Robert L. Davies. Tel: +44 141339 8855. Fax: +441413304600. \\ e-mail: r.l.davies@bio.gla.ac.uk
}

1 Division of Infection and Immunity, Institute of Biomedical and Life Sciences, University of Glasgow, Glasgow G12 8QQ, UK

2 Institute of Molecular Evolutionary Genetics, Pennsylvania State University, University Park, PA 16802, USA
Genetic diversity among 60 British Pasteurella trehalosi isolates representing the four recognized capsular serotypes, T3, T4, T10 and T15, and recovered predominantly from sheep suffering from systemic pasteurellosis, was estimated by analysing electrophoretically demonstrable allelic variation at structural genes encoding 19 enzymes. Thirteen of the loci were polymorphic and 20 distinctive multilocus genotypes (electrophoretic types, ETs) were identified. The population structure of $P$. trehalosi is clonal and its genetic diversity is limited compared with most other pathogenic bacteria. ETs represent clones, and isolates of the same ET were generally associated with the same combination of serotype, LPS type and outer-membrane protein (OMP) type. The genetic diversity of isolates within each of the capsular serotypes varied. Serotype T10 was represented by 18 isolates in two related ETs and exhibited little diversity. By contrast, serotype T15 was represented by 18 isolates in nine ETs and was almost as diverse as the species as a whole. Serotype T4 was represented by 18 isolates in five ETs and was less diverse than serotype T15. Although serotype T3 was more diverse than serotype T15 it was represented by only three isolates. With the exception of the T10 isolates and those recovered from healthy sheep, 35 disease isolates belonged to 16 ETs, each of which was represented by only one to four isolates. The fact that a high proportion of disease is caused by a relatively large number of clones suggests that $\boldsymbol{P}$. trehalosi is essentially an opportunistic pathogen. In addition to having the same capsular structure, isolates belonging to the two T10 clones were characterized by possession of similar, if not identical, 0-antigens (LPS types 2 and 4). The occurrence of 18 serotype T10 isolates in only two ETs suggests that the T10 capsule and type 2/4 0-antigen confer enhanced virulence on members of these two clones. Multilocus enzyme electrophoresis (MLEE) had greater resolving power than did capsule/LPS/OMP analysis, being able to distinguish 20 rather than 14 sub-divisions within $P$. trehalosi. The technique demonstrated genetic identity or non-identity among strains of the same or different serotypes from different geographic localities within the UK and was a useful epidemiological tool.

Keywords: Pasteurella trehalosi, multilocus enzyme electrophoresis, population genetics

\section{INTRODUCTION}

Pasteurella trehalosi, a Gram-negative bacterium be-

Abbreviations: ET, electrophoretic type; MLEE, multilocus enzyme electrophoresis; OMP, outer-membrane protein; UPGMA, unweighted-pair group method with averages; VI Centre, Veterinary Investigation Centre. longing to the family Pasteurellaceae, is a widely occurring pathogen of sheep (Biberstein \& Thompson, 1966; Gilmour \& Gilmour, 1989). It colonizes the tonsils of clinically normal animals (Al-Sultan \& Aitken, 1985; Gilmour et al., 1974) and, particularly under stressful conditions, produces an acute systemic infection affecting the upper alimentary tract and lungs of young 
adults (Gilmour, 1980; Gilmour \& Gilmour, 1989). Traditionally, $P$. trehalosi has been recognized as the $\mathrm{T}$ biotype of the Pasteurella haemolytica complex (Gilmour \& Gilmour, 1989; Mutters et al., 1989; Smith, 1961), but significant biochemical, serological, pathogenic and epidemiological differences between the two biotypes (Biberstein \& Gills, 1962; Gilmour, 1980; Smith, 1961) led to the proposal (Sneath \& Stevens, 1990) that the $T$ biotype be recognized as a distinct species, $P$. trehalosi.

Because $P$. trehalosi has not been widely recognized as a species distinct from $P$. haemolytica, little is known about its biology, including the extent of genetic diversity, epidemiology and virulence mechanisms and their role in pathogenesis. Whereas $P$. trehalosi colonizes the tonsils and produces a systemic disease in young adult sheep, $P$. haemolytica colonizes the nasopharynx and produces pneumonia in sheep of all ages as well as in cattle (Frank, 1989; Gilmour, 1980; Gilmour \& Gilmour, 1989). These important differences in host specificity and pathogenicity suggest that $P$. trehalosi and $P$. haemolytica have different virulence mechanisms. In particular, $P$. trehalosi is likely to possess mechanisms allowing it to invade the tonsils and pharyngeal mucosae, survive within the lymphatics and bloodstream, and spread to other organs (Biberstein \& Thomson, 1966). Differences between P. trehalosi and $P$. haemolytica that may be related to differences in pathogenic mechanisms and host specificity have been described in leukotoxin structure (Gerbig et al., 1992), LPS structure and profiles (Davies \& Quirie, 1996; Lacroix et al., 1993), outer-membrane protein (OMP) profiles (Davies \& Quirie, 1996), and the presence or absence of sialoglycoprotease (Gcp) activity and the $g c p$ gene (Abdullah et al., 1990; Lee et al., 1994).

P. trehalosi has four different capsular polysaccharide structures, T3, T4, T10 and T15, that form the basis of a serotyping scheme used for examining inter-strain variation (Adlam, 1989; Gilmour \& Gilmour, 1989). However, based on a comparison of the LPS and OMP profiles of 60 isolates of $P$. trehalosi, Davies \& Quirie (1996) demonstrated that capsular serotyping does not reveal the full extent of diversity within the species and concluded that it is of limited use in epidemiological studies. Although variation in cell-surface structures, including capsule, LPS and OMPs, forms the basis of important bacterial typing schemes, such variation does not necessarily reflect the underlying genetic relationships between bacteria because it is phenotypic and difficult to relate to allelic variation at specific gene loci (Selander et al., 1986). In contrast, multilocus enzyme electrophoresis (MLEE) is a method that examines genetic diversity within and among populations, has been applied in numerous studies of bacterial population genetics, and is a powerful epidemiological tool (Selander et al., 1986). In particular, the method has been successfully used in studies of other members of the Pasteurellaceae, including Actinobacillus pleuropneumoniae (Møller et al., 1992; Musser et al., 1987), Haemophilus (Actinobacillus) actinomycetemcomitans
(Haubek et al., 1995; Poulsen et al., 1994), and Haemophilus influenzae (Musser et al., 1988a, b).

In the present study, MLEE was used to assess genetic diversity within a sample of 60 isolates of $P$. trehalosi which had been recovered in diverse geographic locations in the UK and had been the subject of a previous investigation of variation in cell-surface components (Davies \& Quirie, 1996). The objective was to develop a population genetic framework for P. trehalosi that could be used to (1) identify clonal groups involved in disease, (2) correlate the presence of specific cellsurface structures with virulent clonal groups, thereby identifying those structures as putative virulence determinants, and (3) determine the geographic distribution and abundance of the various clonal groups and assess the usefulness of MLEE for epidemiological studies.

\section{METHODS}

Bacterial isolates and growth conditions. Sixty isolates of $P$. trehalosi were examined, all of which, with the exception of one from a calf, had been recovered from sheep. Except for seven strains from the National Collection of Type Cultures (NCTC) and two from the Moredun Research Institute (MRI), the isolates were obtained from nine Veterinary Investigation (VI) Centres in Scotland (five), England (two) and Wales (two). The NCTC cultures were collected 25-35 years ago. Information concerning the disease status of the host animals and tissue of origin of the isolates are provided by Davies \& Quirie (1996). Properties of the isolates that are of direct relevance to the present study, including electrophoretic type (ET), capsular serotype, LPS type and OMP type, are presented in Table 1.

Growth of bacteria and electrophoresis of enzymes. Each isolate was grown overnight at $37^{\circ} \mathrm{C}$ in $150 \mathrm{ml}$ brain-heart infusion broth (Oxoid) on an orbital shaker (120 r.p.m.). Following incubation, samples from each culture were plated onto blood agar (brain-heart infusion agar containing $5 \%$, $\mathrm{v} / \mathrm{v}$, defibrinated sheep's blood) to check for contamination. Bacteria were harvested by centrifugation at $5000 \mathrm{~g}$ for $10 \mathrm{~min}$ at $4{ }^{\circ} \mathrm{C}$, resuspended in $2 \mathrm{ml} 50 \mathrm{mM}$ Tris/ $\mathrm{HCl}$ buffer containing $1 \mathrm{mM}$ EDTA and $0.05 \mathrm{mM}$ NADP (pH 8.0), and disrupted by three $10 \mathrm{~s}$ cycles of sonication with $10 \mathrm{~s}$ intervals of ice-water cooling. Unbroken cells were removed by centrifugation at $15000 \mathrm{~g}$ for $20 \mathrm{~min}$ at $4{ }^{\circ} \mathrm{C}$ and the supernatant (lysate) was divided into two aliquots and stored at $-70^{\circ} \mathrm{C}$.

Lysates were electrophoresed on starch gels and selectively stained for 19 metabolic enzymes by the methods described by Selander et al. (1986). The enzymes studied were as follows: acid phosphatase (ACP), adenylate kinase (ADK), carbamate kinase (CAK), esterase-1 and -2 (ES1 and ES2), glyceraldehyde3-phosphate dehydrogenase (G3P), glutamate dehydrogenase (GLD), glucose-6-phosphate dehydrogenase (G6P), glutamicoxalacetic transaminase (GOT), malate dehydrogenase (MDH), mannitol-1-phosphate dehydrogenase (M1P), nucleoside phosphorylase (NSP), 6-phosphogluconate dehydrogenase (6PG), phenylalanyl-leucine peptidase-1 and -2 (PP1 and PP2), leucine-glycine-glycine peptidase (LGG), phosphoglucose isomerase (PGI), phosphoglucomutase (PGM), and shikimate dehydrogenase (SKD). GLD, G6P, PGM and SKD were electrophoresed in buffer system A; GOT was electrophoresed in buffer system $B ; A D K, M D H$ and M1P were electrophoresed in buffer system C; ACP, 6PG, PP1, PP2 and 
Table 1. Characteristics of $P$. trehalosi isolates

\begin{tabular}{|c|c|c|c|c|c|c|}
\hline ET & $\begin{array}{l}\text { Reference } \\
\text { isolate }\end{array}$ & $\begin{array}{l}\text { No. of } \\
\text { isolates }\end{array}$ & $\begin{array}{l}\text { Capsular } \\
\text { serotype }\end{array}$ & $\begin{array}{l}\text { LPS } \\
\text { type }\end{array}$ & $\begin{array}{l}\text { OMP } \\
\text { type }\end{array}$ & Origin of isolates (no.) \\
\hline \multicolumn{7}{|c|}{ Cluster A1 } \\
\hline 1 & PH728 & 2 & T4 & 3 & 1 & Dumfries $(2)$ \\
\hline 2 & $\mathrm{PH} 246$ & 5 & $\mathrm{~T} 4$ & 3 & 1 & NCTC (2), Penrith (3) \\
\hline 2 & PH636 & 3 & T4 & 6 & 1 & Edinburgh $(3)$ \\
\hline 3 & PH356 & 7 & T10 & 2 & 1 & $\begin{array}{l}\text { Aberystwyth (1), Auchincruvie (1), } \\
\text { Carmarthen (2), Penrith (2), St Boswells (1) }\end{array}$ \\
\hline 3 & PH662 & 2 & T10 & 4 & 1 & Carmarthen $(2)$ \\
\hline 4 & PH492 & 8 & T10 & 2 & 1 & $\begin{array}{l}\text { Aberystwyth (1), Carmarthen (1), Dumfries } \\
\text { (1), Edinburgh (1), Penrith (3), St Boswells (1) }\end{array}$ \\
\hline 4 & PH252 & 1 & $\mathrm{~T} 10$ & 2 & 2 & NCTC (1) \\
\hline 5 & PH328 & 4 & $\mathrm{~T} 4$ & 4 & 1 & $\begin{array}{l}\text { Aberystwyth (1), Carmarthen (1), Edinburgh } \\
\text { (1), Penrith (1) }\end{array}$ \\
\hline 6 & PH750 & 3 & T15 & 4 & 1 & Penrith (3) \\
\hline 7 & PH520 & 2 & T15 & 4 & 1 & St Boswells (1), MRI (1) \\
\hline \multicolumn{7}{|c|}{ Cluster A2 } \\
\hline 8 & PH604 & 1 & T3 & $\mathbf{R}$ & 4 & Edinburgh (1) \\
\hline 9 & $\mathrm{PH} 780$ & 1 & $\mathrm{~T} 15$ & 3 & 2 & Carmarthen (1) \\
\hline 10 & $\mathrm{PH} 722$ & 1 & $\mathrm{~T} 15$ & 3 & 1 & Carmarthen (1) \\
\hline 11 & PH718 & 1 & $\mathrm{~T} 15$ & 3 & 1 & Carmarthen (1) \\
\hline 12 & PH664 & 2 & $\mathrm{~T} 15$ & 3 & 1 & Carmarthen (2) \\
\hline \multicolumn{7}{|c|}{ Cluster B } \\
\hline 13 & PH732 & 3 & $\mathrm{~T} 4$ & 3 & 2 & Penrith (3) \\
\hline 14 & PH688 & 1 & $\mathrm{~T} 4$ & 3 & 1 & Carmarthen (1) \\
\hline 15 & PH70 & 4 & T15 & 3 & 3 & NCTC (3), Penrith (1) \\
\hline \multicolumn{7}{|c|}{ Cluster C } \\
\hline 16 & PH694 & 2 & T15 & 3 & 2 & Aberdeen $(2)$ \\
\hline 17 & PH648 & 2 & $\mathrm{~T} 15$ & 5 & 1 & Carmarthen (1), Shrewsbury (1) \\
\hline \multicolumn{7}{|c|}{ Cluster D } \\
\hline 18 & PH792 & 3 & UT & 3 & 3 & Penrith (3) \\
\hline \multicolumn{7}{|c|}{ Cluster E } \\
\hline 19 & PH68 & 1 & T3 & 1 & 1 & NCTC (1) \\
\hline 20 & PH674 & 1 & T3 & 1 & 1 & MRI (1) \\
\hline
\end{tabular}

LGG were electrophoresed in buffer system E; CAK, ES1, ES2, G3P, NSP and PGI were electrophoresed in buffer system I.

For each enzyme, distinctive mobility variants were designated as electromorphs and numbered in order of decreasing rate of anodal migration. Electromorphs of an enzyme were equated with alleles at the corresponding structural gene locus, and an absence of enzyme activity was attributed to a null allele, designated as 0 . Because most isolates showed activity for all 19 enzymes, it was assumed that the corresponding structural gene loci are located on the chromosome rather than on plasmids. Isolates with identical combinations of alleles at the 19 enzyme loci corresponded to a unique multilocus genotype and were designated as an ET.

Statistical analysis. Genetic diversity at an enzyme locus $(b)$ among either ETs or isolates was calculated from the allele frequencies by $h=\left(1-\Sigma x_{i}^{2}\right)(n / n-1)$ where $x_{i}$ is the frequency of the $i$ th allele and $n$ is the number of ETs or isolates (Selander et al., 1986). Mean genetic diversity per locus $(H)$ is the arithmetic average of $b$ values for all loci. Genetic distance between pairs of ETs was expressed as the proportion of enzyme loci at which different alleles were represented (mismatches). A dendrogram showing relationships among
ETs was constructed from the matrix of distance coefficients by the unweighted-pair group method with averages (UPGMA) clustering strategy (Sneath \& Sokal, 1973) with the program MEGA (Molecular Evolutionary Genetics Analysis). Various statistical programs, together with a conversion program for MEGA, were provided by T. S. Whittam (Institute of Molecular and Evolutionary Genetics, Pennsylvania State University).

Capsular serotyping. The method described by Fraser \& Donachie (1983) was used for capsular serotyping.

LPS and OMP profiles. Methods for the analysis of LPS and OMP profiles have been described by Davies \& Quirie (1996).

\section{RESULTS}

\section{Overall genetic diversity}

In the collection of 60 isolates of $P$. trehalosi examined by MLEE, 13 of the 19 enzyme loci were polymorphic for two to seven alleles encoding electrophoretically distinguishable variant proteins, and six loci were monomorphic (Table 2). The mean number of alleles 
Table 2. Allele profiles at 19 enzyme loci in $20 \mathrm{ET}$ s of $P$. trehalosi

Abbreviations: ADK, adenylate kinase; $\mathrm{MDH}$, malate dehydrogenase; M1P, mannitol-1-phosphate dehydrogenase; CAK, carbamate kinase; ES1 and ES2, esterase; G3P, glyceraldehyde-3-phosphate dehydrogenase; NSP, nucleoside phosphorylase; PGI, phosphoglucose isomerase; GOT, glutamic-oxalacetic transaminase; GLD, glutamate dehydrogenase; G6P, glucose-6-phosphate dehydrogenase; PGM, phosphoglucomutase; SKD, shikimate dehydrogenase; ACP, acid phosphatase; 6PG, 6-phosphogluconate dehydrogenase; PP1 and PP2, phenylalanyl-leucine peptidase; LGG, leucine-glycine-glycine peptidase.

\begin{tabular}{|c|c|c|c|c|c|c|c|c|c|c|c|c|c|c|c|c|c|c|c|c|c|}
\hline \multirow[t]{2}{*}{ ET } & \multirow{2}{*}{$\begin{array}{l}\text { Reference } \\
\text { isolate }\end{array}$} & \multirow{2}{*}{$\begin{array}{l}\text { No. of } \\
\text { isolates }\end{array}$} & \multicolumn{19}{|c|}{ Allele at the indicated enzyme locus } \\
\hline & & & ADK & $\mathrm{MDH}$ & M1P & CAK & ES1 & ES2 & G3P & NSP & PGI & GOT & GLD & G6P & PGM & SKD & ACP & 6PG & PP1 & PP2 & LGG \\
\hline 1 & $\mathrm{PH} 728$ & 2 & 2 & 1 & 1 & 2 & 2 & 6 & 1 & 1 & 1 & 3 & 2 & 2 & 1 & 2 & 1 & 3 & 4 & 1 & 4 \\
\hline 2 & PH246 & 8 & 2 & 1 & 1 & 2 & 2 & 5 & 1 & 1 & 1 & 3 & 2 & 2 & 1 & 2 & 1 & 3 & 4 & 1 & 4 \\
\hline 3 & PH356 & 9 & 2 & 1 & 1 & 2 & 2 & 0 & 1 & 1 & 1 & 3 & 1 & 2 & 1 & 2 & 1 & 3 & 4 & 1 & 4 \\
\hline 4 & PH492 & 9 & 2 & 1 & 1 & 2 & 2 & 0 & 1 & 1 & 1 & 1 & 1 & 2 & 1 & 2 & 1 & 3 & 4 & 1 & 4 \\
\hline 5 & PH 328 & 5 & 2 & 1 & 1 & 2 & 2 & 0 & 1 & 1 & 1 & 1 & 2 & 2 & 1 & 1 & 1 & 3 & 4 & 1 & 4 \\
\hline 6 & $\mathrm{PH} 750$ & 3 & 2 & 1 & 1 & 2 & 2 & 0 & 1 & 1 & 1 & 1 & 1 & 2 & 1 & 1 & 1 & 3 & 4 & 1 & 4 \\
\hline 7 & PH520 & 2 & 2 & 1 & 1 & 2 & 2 & 0 & 1 & 1 & 1 & 1 & 1 & 1 & 1 & 1 & 1 & 3 & 4 & 1 & 4 \\
\hline 8 & $\mathrm{PH} 604$ & 1 & 2 & 1 & 1 & 2 & 1 & 5 & 1 & 1 & 1 & 3 & 2 & 2 & 1 & 3 & 1 & 1 & 4 & 1 & 4 \\
\hline 9 & $\mathrm{PH} 780$ & 1 & 2 & 1 & 1 & 2 & 1 & 3 & 1 & 1 & 1 & 3 & 1 & 2 & 1 & 3 & 1 & 3 & 4 & 1 & 4 \\
\hline 10 & PH722 & 1 & 2 & 1 & 1 & 2 & 1 & 3 & 1 & 1 & 1 & 3 & 2 & 2 & 1 & 3 & 1 & 2 & 4 & 1 & 4 \\
\hline 11 & $\mathrm{PH} 718$ & 1 & 2 & 1 & 1 & 2 & 1 & 3 & 1 & 1 & 1 & 1 & 2 & 2 & 1 & 3 & 1 & 3 & 4 & 1 & 4 \\
\hline 12 & PH664 & 2 & 2 & 1 & 1 & 2 & 1 & 3 & 1 & 1 & 1 & 3 & 2 & 2 & 1 & 3 & 1 & 3 & 4 & 1 & 4 \\
\hline 13 & PH732 & 3 & 2 & 1 & 1 & 2 & 1 & 4 & 1 & 1 & 1 & 1 & 2 & 2 & 1 & 3 & 1 & 3 & 3 & 1 & 3 \\
\hline 14 & PH688 & 1 & 2 & 1 & 1 & 2 & 2 & 2 & 1 & 1 & 1 & 1 & 2 & 2 & 1 & 3 & 1 & 3 & 1 & 1 & 1 \\
\hline 15 & PH70 & 4 & 2 & 1 & 1 & 2 & 2 & 6 & 1 & 1 & 1 & 1 & 2 & 2 & 1 & 3 & 1 & 3 & 1 & 1 & 1 \\
\hline 16 & PH694 & 2 & 2 & 1 & 1 & 2 & 2 & 1 & 1 & 1 & 1 & 3 & 2 & 2 & 1 & 3 & 1 & 1 & 1 & 2 & 1 \\
\hline 17 & PH648 & 2 & 2 & 1 & 1 & 2 & 2 & 0 & 1 & 1 & 1 & 4 & 2 & 2 & 1 & 3 & 1 & 3 & 5 & 2 & 5 \\
\hline 18 & PH792 & 3 & 2 & 1 & 2 & 2 & 2 & 6 & 1 & 1 & 1 & 2 & 2 & 2 & 1 & 3 & 1 & 4 & 2 & 1 & 2 \\
\hline 19 & PH68 & 1 & 1 & 1 & 1 & 1 & 2 & 0 & 1 & 1 & 1 & 5 & 1 & 2 & 1 & 2 & 1 & 4 & 3 & 1 & 3 \\
\hline 20 & PH674 & 1 & 1 & 1 & 1 & 1 & 2 & 0 & 1 & 1 & 1 & 5 & 1 & 2 & 1 & 2 & 1 & 3 & 3 & 1 & 3 \\
\hline
\end{tabular}

Table 3. Allele frequencies and genetic diversity $(h)$ at 19 enzyme loci in 20 ETs of P. trehalosi

Enzyme abbreviations are defined in the legend to Table 2.

\begin{tabular}{|c|c|c|c|c|c|c|c|c|}
\hline \multirow{2}{*}{$\begin{array}{l}\text { Enzyme } \\
\text { locus }\end{array}$} & \multicolumn{7}{|c|}{ Frequency of the indicated allele: } & \multirow[t]{2}{*}{$h^{*}$} \\
\hline & 1 & 2 & 3 & 4 & 5 & 6 & $\mathbf{0}$ & \\
\hline ADK & $0 \cdot 100$ & $0 \cdot 900$ & & & & & & $0 \cdot 189$ \\
\hline $\mathrm{MDH}$ & $1 \cdot 000$ & & & & & & & 0.000 \\
\hline M1P & $0 \cdot 950$ & $0 \cdot 050$ & & & & & & $0 \cdot 100$ \\
\hline CAK & $0 \cdot 100$ & $0 \cdot 900$ & & & & & & $0 \cdot 189$ \\
\hline ES1 & $0 \cdot 300$ & $0 \cdot 700$ & & & & & & 0.442 \\
\hline ES2 & 0.050 & $0 \cdot 050$ & $0 \cdot 200$ & 0.050 & $0 \cdot 100$ & $0 \cdot 150$ & $0 \cdot 400$ & 0.800 \\
\hline G3P & $1 \cdot 000$ & & & & & & & $0 \cdot 000$ \\
\hline NSP & $1 \cdot 000$ & & & & & & & 0.000 \\
\hline PGI & $1 \cdot 000$ & & & & & & & 0.000 \\
\hline GOT & $0 \cdot 400$ & $0 \cdot 050$ & $0 \cdot 400$ & 0.050 & $0 \cdot 100$ & & & 0.700 \\
\hline GLD & $0 \cdot 350$ & 0.650 & & & & & & 0.479 \\
\hline G6P & 0.050 & 0.950 & & & & & & $0 \cdot 100$ \\
\hline PGM & 1.000 & & & & & & & 0.000 \\
\hline SKD & $0 \cdot 150$ & $0 \cdot 300$ & 0.550 & & & & & 0.616 \\
\hline ACP & 1.000 & & & & & & & 0.000 \\
\hline $6 \mathrm{PG}$ & $0 \cdot 100$ & 0.050 & 0.750 & $0 \cdot 100$ & & & & 0.437 \\
\hline PP1 & $0 \cdot 150$ & 0.050 & $0 \cdot 150$ & 0.600 & 0.050 & & & 0.621 \\
\hline PP2 & 0.900 & $0 \cdot 100$ & & & & & & $0 \cdot 189$ \\
\hline LGG & $0 \cdot 150$ & 0.050 & $0 \cdot 150$ & 0.600 & 0.050 & & & 0.621 \\
\hline
\end{tabular}

* Mean genetic diversity per locus, $H=0 \cdot 289$. 


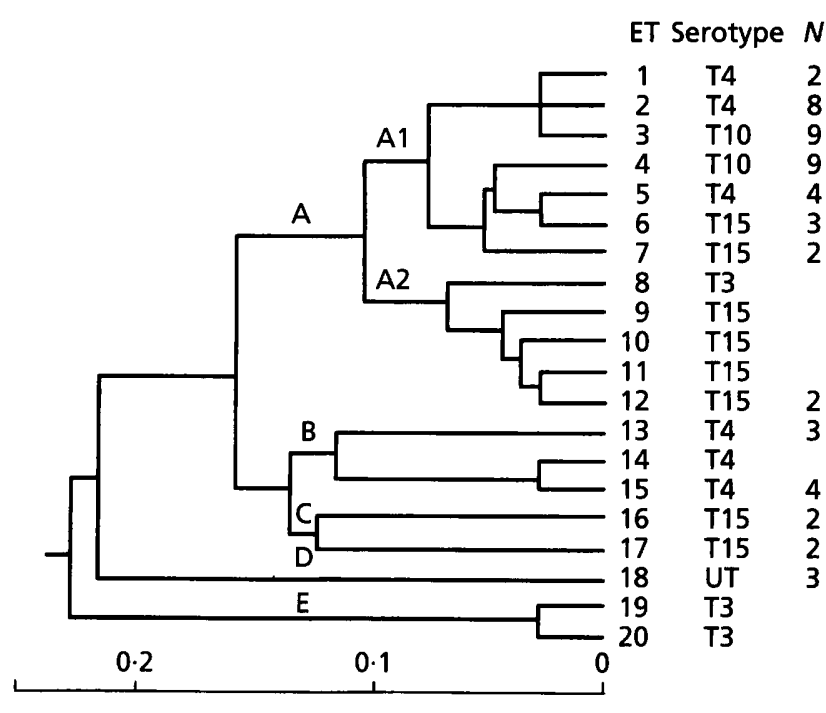

Genetic distance

Fig. 1. Genetic relationships of ETs of $P$. trehalosi isolates. The dendrogram was generated by UPGMA clustering from a matrix of coefficients of pairwise genetic distances based on 19 enzyme loci. ETs are numbered sequentially from top to bottom in the order of listing in Table $2 . N$ is the number of isolates in each ET represented by multiple isolates; all other ETs were represented by single isolates. Five lineages, identified at a genetic distance of 0.14 , are indicated by the letters $A-E$; lineages $\mathrm{A} 1$ and $\mathrm{A} 2$ diverged at a genetic distance of $0 \cdot 1$.

Table 4. Mean genetic diversity $(H)$ at 19 enzyme loci among ETs of $P$. trehalosi classified by serotype

\begin{tabular}{|lccccc|}
\hline \multirow{2}{*}{ Serotype } & \multicolumn{2}{c}{ No. of: } & & \multicolumn{2}{c|}{ Diversity among ETs } \\
\cline { 2 - 3 } \cline { 5 - 6 } & Isolates & ETs & & $H$ & Variance \\
\hline T4 & 18 & 5 & & 0.221 & 0.080 \\
T10 & 18 & 2 & & 0.053 & 0.053 \\
T15 & 18 & 9 & & 0.263 & 0.064 \\
T3 & 3 & 3 & & 0.368 & 0.084 \\
Untypable & 3 & 1 & & 0.000 & 0.000 \\
\hline
\end{tabular}

per locus was 2.6. Twenty ETs were identified (Table 2), among which the mean genetic diversity per locus $(H)$ was 0.289 (Table 3 ). There was less diversity among the isolates $(H=0.225)$, because 13 of the ETs were represented by two or more isolates (mean $4 \cdot 1$ isolates; range $2-9$ ).

\section{Genetic relationships among multilocus genotypes}

Estimates of the genetic relationships among the $20 \mathrm{ET}$ s are summarized in the dendrogram in Fig. 1. The smallest observed genetic distance $(0.03)$ between ETs corresponds to a single locus difference. At a genetic distance of 0.14 there were five lineages or clusters of lineages designated A-E (Fig. 1). Cluster A consisted of 12 ETs distributed in two sub-clusters, A1 and A2, which separated at a genetic distance of $0 \cdot 1$. Lineage A1 consisted of $37(62 \%)$ isolates in seven ETs, whereas lineage A2 consisted of only six $(10 \%)$ isolates in five ETs. Clusters B and C diverged from cluster $A$ at a genetic distance of $0 \cdot 16$ and consisted of $12(20 \%)$ isolates in five ETs. Clusters D and E diverged from clusters $\mathrm{A}-\mathrm{C}$ at genetic distances of 0.22 and 0.23 , respectively, and consisted of five isolates in three ETs.

\section{Genetic variation in relation to capsular serotypes, LPS types and OMP types}

Estimates of the extent of genetic variation among ETs of the various capsular serotypes are presented in Table 4. Diversity $(H)$ among ETs of a given serotype was, on average, $0 \cdot 226$, which is $78 \%$ of that in the total sample of 20 ETs. It ranged from 0.053 for serotype T10, represented by 18 isolates in two closely related ETs in cluster A, to 0.368 for serotype T3, represented by three isolates in three ETs. There were no cases of isolates of different capsular serotypes occurring within the same ET. The three untypable (UT) isolates, which originated from the same animal and probably represent a new serotype, were genetically identical.

Specific combinations of capsular serotype, LPS type and OMP type were associated with each ET or closely related groups of ETs (Table 1). Within cluster A1, isolates of ETs 2-4 could be sub-divided on the basis of variation in either LPS (ETs 2 and 3) or OMP (ET 4) type. ETs 1 and 2, 3 and 4, and 5-7, formed three distinct groups based on the associations of serotypes, LPS types and OMP types. By contrast, ETs within cluster A2 were more homogeneous, with the exception of ET 8, in terms of their capsular serotypes, LPS types and OMP types. Clusters B and C consisted of serotype T4 and T15 isolates in five ETs. These isolates generally possessed the same LPS types as those in cluster A2 (i.e. LPS type 3), but had more variable OMP types. Clusters $D$ and $E$ included the group of previously unrecognized untypable isolates (ET 18), together with two serotype T3 isolates in ETs 19 and 20.

In most of the cases described above, isolates having the same capsule/LPS/OMP types belonged to the same or to closely related multilocus genotypes. However, a small number of isolates had identical capsule/LPS/ OMP types but belonged to unrelated ETs. For example, isolates with capsular serotype T4/LPS type 3/OMP type 1 occurred in ETs 1,2 and 14; similarly, isolates having capsular serotype T15/LPS type 3/OMP type 2 occurred in ETs 9 and 16.

\section{Genetic diversity within geographic region}

The geographical distribution of the isolates is summarized in Table 1 . Those isolates of ETs in lineage A1 were the most numerous and geographically widespread. In particular, ETs 3 and 4, which consisted of 18 serotype T10 isolates and accounted for $30 \%$ of the total number of isolates, originated from seven of the nine VI Centres (Aberystwyth, Auchincruvie, Carmarthen, 
Dumfries, Edinburgh, Penrith and St Boswells) and represented two geographically widespread and important clonal groups. ET 5 consisted of only four isolates, but each was recovered by a different VI Centre in Scotland, England or Wales (Aberystwyth, Carmarthen, Edinburgh and Penrith) and was therefore also geographically widely distributed. Other ETs in this lineage consisted of only two to three isolates which originated from one or two generally different VI Centres; for example ET 1 isolates originated from Dumfries, ET 2 isolates originated from Edinburgh and Penrith, ET 6 isolates originated from Penrith and ET 7 isolates originated from St Boswells (Table 1). By contrast, lineage A2 included four ETs (ETs 9-12) that were represented by only one or two isolates recovered from the same VI Centre, Carmarthen. Clusters B and C consisted of ETs 13-17 and included isolates from Aberdeen, Carmarthen, Penrith and Shrewsbury. However, with the exception of ET 17, each ET was represented by isolates from a single VI Centre only. The previously unrecognized untypable isolates belonged to ET 18 and were recovered from a single VI Centre, Penrith.

\section{DISCUSSION}

\section{Clonal nature of $\boldsymbol{P}$. trehalosi}

The clone concept of bacterial population structure, first demonstrated in Escherichia coli (Ochman \& Selander, 1984; Ørskov et al., 1976), is now well accepted, athough it is also recognized that not all bacterial species have a clonal population structure (Go et al., 1996; MaynardSmith et al., 1993; Selander \& Musser, 1990). The recovery of the same multilocus genotypes at different localities and times within the UK suggests that chromosomal recombination occurs relatively infrequently in natural populations of $P$. trehalosi and that, consequently, the genetic structure of the species is basically clonal. For example, isolates of ETs 3, 4 and 5 were recovered from VI Centres in Scotland, England and Wales; and isolates of ETs 2 and 15, which included NCTC strains and recent field isolates, were recovered at least 25-35 years apart. The fact that isolates of the same capsule/LPS/OMP types frequently belong to the same ET, or to closely related ETs, is also consistent with a basically clonal population structure. ETs 3 and 4 , which included $30 \%$ of the total number of isolates, were recovered from seven of the nine VI Centres in Scotland, England and Wales and represent two important geographically widespread clones.

\section{Genetic diversity compared with that of other bacteria}

$P$. trehalosi is genetically less diverse $(H=0.289)$ than most other species of pathogenic bacteria that have been examined, with the exceptions of Bordetella spp. ( $H=$ 0.284) (Musser et al., 1986) and Staphylococcus aureus $(H=0.289)$ (Musser \& Selander, 1990). The restricted diversity of $P$. trehalosi could, in theory, be explained by a low mutation rate, recent evolutionary origin, niche specialization or small effective population size. The role that a low mutation rate may have is impossible to assess in the absence of data on the spontaneous mutation rate of this organism. That $P$. trehalosi colonizes the tonsils of, and causes disease only in, sheep indicates a high level of tissue tropism and host specificity, which, in turn, might suggest that niche specialization is a factor involved in the low genetic diversity of this pathogen. But studies of a number of other bacteria, including E. coli, Neisseria meningitidis, Legionella pneumophila and Bordetella bronchiseptica, have failed to demonstrate a relationship between niche width and genetic diversity (Musser et al., 1987). A possible explanation for the low genetic diversity of $P$. trehalosi is a recent evolutionary origin and consequent low effective population size. However, the fact that the sample was derived from a relatively small geographic area and was represented by isolates recovered only from diseased animals might also account for the low diversity. Since $P$. trehalosi is recovered at high rates from the tonsils of healthy sheep (Al-Sultan \& Aitken, 1985; Gilmour et al., 1974), studies of isolates from healthy animals and from other countries might reveal a higher diversity. In support of this, Møller et al. (1992) obtained a mean genetic diversity of only 0.247 for $A$. pleuropneumoniae isolates obtained from Denmark, whereas Musser et al. (1987) reported a value of 0.370 for A. pleuropneumoniae isolates recovered from 14 different countries.

\section{Genetic variation in relation to capsular serotypes, LPS types and OMP types}

In a previous study of LPS and OMP variation within $P$. trehalosi, Davies \& Quirie (1996) suggested that serotype T10 isolates are less diverse than those of serotypes T4 and T15. This conclusion was confirmed in the present investigation. Serotype T15 $(H=0 \cdot 263)$ isolates belonged to nine ETs occurring in each of the clusters A, $B$ and $C$, and were more diverse than isolates of serotypes T4 or T10. Serotype T4 $(H=0 \cdot 221)$ isolates belonged to five ETs occurring in lineages $\mathrm{A} 1$ and $\mathrm{B}$, whereas serotype T10 $(H=0.053)$ isolates belonged to only two ETs, both in lineage A1. The T4 and T15 capsules are structurally very similar, differing only in the linkage of a phosphate group to galactose at $\mathrm{C} 4$ in the T4 capsule and at C6 in the T15 capsule (Adlam et al., 1985a, b). The structure of the T10 capsule is not known, but, based on the genetic relationships of $P$. trehalosi isolates, it seems likely that it may more closely resemble the T4 capsule than that of T15. Although, in some cases, closely related clusters of ETs possessed different capsules (e.g. ETs 4-7), each ET was represented by only a single capsular serotype. This situation is similar to that in H. influenzae (Musser et al., 1988a, b) and A. pleuropneumoniae (Musser et al., 1987) and differs markedly from that in E. coli (Caugant et al., 1985) and $N$. meningitidis (Caugant et al., 1987) in which many ETs are represented by isolates of two or more polysaccharide capsule serotypes. 
The O-antigen structures of LPS from T4 and T10 isolates (Perry \& Babiuk, 1984; Richards \& Leitch, 1989) and from T3 and T15 isolates (Lacroix et al., 1993; Leitch \& Richards, 1988), respectively, have been shown to be identical, although Davies \& Quirie (1996) demonstrated that isolates of the same capsular serotype may have different $\mathrm{O}$-antigen profiles. It was previously suggested that the $\mathrm{O}$-antigen side-chains of type 2 and type 4 LPS are identical, and that these LPS types differ only in the nature of the core-oligosaccharide region (Davies \& Quirie, 1996). The present study demonstrated that isolates possessing LPS types 2 and 4 are genetically related $(H=0.095$; results not shown); isolates possessing these LPS types belonged to the related ETs 3-7 in sub-cluster A1 (Table 1 and Fig. 1). The type $2 / 4 \mathrm{O}$-antigen is therefore an important marker of this genetically related group of ETs which was represented by $27(45 \%)$ isolates. By comparison, isolates possessing LPS type 3 were genetically more diverse $(H=0.248$; results not shown), being distributed in 11 ETs occurring in clusters A-D. Based on the MLEE data, it appears that LPS types 5 and 6 might be related to LPS type 3, since isolates of LPS types 5 and 6 were genetically related to those of LPS type 3 .

Only three major OMP profiles were present in the $P$. trehalosi population, and isolates of the same OMP type were not necessarily genetically related. For example, OMP type 1, which occurred in $75 \%$ of isolates, was found in all clusters except D; OMP type 2 occurred in four ETs $(4,9,13$ and 16) in four lineages; and OMP type 3 occurred in two ETs (15 and 18) in two lineages.

The findings of the present study indicate that capsular serotyping is an ineffective method for assessing the genetic relationships of isolates within P. trehalosi and is of limited use in epidemiological studies. MLEE identified distinctive multilocus genotypes among isolates of the same serotype obtained from the same VI Centre (e.g. T15 isolates of ETs 9-12 from Carmarthen), differentiated between isolates of the same serotype from different VI Centres (e.g. T4 isolates of ETs 1, 13 and 14 from Dumfries, Penrith and Carmarthen, respectively) and demonstrated clonal identity of isolates of the same serotype from different VI Centres (e.g. T4 isolates of ET 5 from Aberystwyth, Carmarthen, Edinburgh and Penrith). MLEE had greater resolving power than capsule/LPS/OMP typing, being able to distinguish 20 groups rather than 14 and to differentiate between isolates of the same capsule/LPS/OMP type. However, in three cases (ETs 2, 3 and 4) LPS and OMP analysis differentiated between isolates of the same multilocus genotypes. The present study demonstrated that the three untypable isolates (ET 18) were genetically distinct, confirming that these isolates probably represent a new serotype.

\section{Genetic variation in relation to disease}

In those pathogenic bacteria that have a clonal population structure, the majority of cases of serious disease is caused by a small proportion of the total number of extant clones (Selander \& Musser, 1990). With the exception of nine isolates that were either recovered from healthy sheep (two isolates) or were of unknown origin (seven isolates), 51 of the total sample of $60 \mathrm{P}$. trehalosi isolates were recovered from sheep diagnosed as suffering from systemic infection (40 isolates) or pneumonia (11 isolates) (for further information see Davies \& Quirie, 1996). Furthermore, with the exception of ETs 19 and 20, all of the ETs were represented by one or more isolates that had originated from diseased sheep. Discounting isolates representing the two T10 clones (ETs 3 and 4), 35 isolates (58\%) representing $16 \mathrm{ETs}$, each of which included just one to four isolates, were found to be associated with disease. With the exception of the T10 clones, therefore, it appears that there is no significant variation in pathogenic potential among the genetic divisions of $P$. trehalosi. The observed lack of association of specific multilocus genotypes with disease suggests that the role of $P$. trehalosi in systemic and pneumonic pasteurellosis in sheep is largely opportunistic. It has been postulated (Gilmour, 1980) that disease outbreaks caused by $P$. trehalosi may be related to stress associated with husbandry changes, such as the movement of sheep and change of diet in the autumn. In addition, experimental reproduction of infection by $P$. trehalosi is difficult to induce in sheep (Gilmour, 1978). These observations are consistent with the conclusion of the present study that $P$. trehalosi is primarily an opportunistic pathogen. However, the occurrence of 18 serotype T10 isolates in only two ETs suggests a higher degree of virulence for these isolates. In addition to having the same capsular structure, the two T10 clones were characterized by possession of similar, if not identical, O-antigens (LPS types 2 and 4). These data suggest, therefore, that the T10 capsule and type 2/4 O-antigen confer enhanced virulence on members of these two clones. Clearly, further work is required to elucidate the precise role in the disease process of the different cell-surface structures of this pathogen.

\section{ACKNOWLEDGEMENTS}

This study was supported by a Wellcome Biodiversity Fellowship to R. L. Davies (Ref. 038464/Z/93/Z/REH/ $M W)$. We are grateful for the assistance and co-operation of staff at the following British Veterinary Investigation Centres for the provision of isolates: Aberdeen, Auchincruvie, Dumfries, Edinburgh, St Boswells (Scotland), Penrith, Shrewsbury (England), Aberystwyth and Carmarthen (Wales).

\section{REFERENCES}

Abdullah, K. M., Lo, R. Y. C. \& Mellors, A. (1990). Distribution of glycoprotease activity and the glycoprotease gene among serotypes of Pasteurella haemolytica. Biochem Soc Trans 18, 901-903.

Adlam, C. (1989). The structure, function and properties of cellular and extracellular components of Pasteurella haemolytica. In Pasteurella and Pasteurellosis, pp. 75-92. Edited by C. F. Adlam \& J. M. Rutter. London: Academic Press. 
Adlam, C., Knights, J. M., Mugridge, A., Lindon, J. C \& Williams, J. M. (1985a). Purification, characterization and immunological properties of the serotype-specific capsular polysaccharide of Pasteurella haemolytica (serotype T4) organisms. J Gen Microbiol 131, 387-394.

Adlam, C., Knights, J. M., Mugridge, A., Lindon, J. C., Williams, J. M. \& Beesley, J. E. (1985b). Purification, characterization and immunological properties of the capsular polysaccharide of Pasteurella haemolytica serotype T15: its identity with the K62 (K2ab) capsular polysaccharide of Escherichia coli and the capsular polysaccharide of Neisseria meningitidis serogroup $\mathrm{H}$. J Gen Microbiol 131, 1963-1972.

Al-Sultan, I. I. \& Aitken, I. D. (1985). The tonsillar carriage of Pasteurella haemolytica in lambs. J Comp Pathol 95, 193-210.

Biberstein, E. L. \& Gills, M. G. (1962). The relation of the antigen types to the A and T types of Pasteurella haemolytica. J Comp Pathol 72, 316-320.

Biberstein, E. L. \& Thompson, D. A. (1966). Epidemiological studies on Pasteurella haemolytica in sheep. J Comp Pathol 76, 83-94.

Caugant, D. A., Levin, B. R., Ørskov, I., Ørskov, F., Eden, C. S. \& Selander, R. K. (1985). Genetic diversity in relation to serotype in Escherichia coli. Infect Immun 49, 407-413.

Caugant, D. A., Mocca, L. F., Frasch, C. E., Frøholm, L. O., Zollinger, W. D. \& Selander, R. K. (1987). Genetic structure of Neisseria meningitidis populations in relation to serogroup, serotype, and outer membrane protein pattern. J Bacteriol 169, 2781-2792.

Davies, R. L. \& Quirie, M. (1996). Intra-specific diversity within Pasteurella trehalosi based on variation of capsular polysaccharide, lipopolysaccharide and outer-membrane proteins. Microbiology 142, 551-560.

Frank, G. H. (1989). Pasteurellosis of cattle. In Pasteurella and Pasteurellosis, pp. 197-222. Edited by C. F. Adlam \& J. M. Rutter. London: Academic Press.

Fraser, J. \& Donachie, W. (1983). Rapid indirect haemagglutination test for serotyping Pasteurella haemolytica. J Clin Microbiol 18, 206-207.

Gerbig, D. G., Cameron, M. R., Struck, D. K. \& Moore, R. N. (1992). Characterization of a neutralizing monoclonal antibody to Pasteurella haemolytica leukotoxin. Infect Immun 60, 1734-1739.

Gilmour, N. J. L. (1978). Pasteurellosis in sheep. Vet Rec 102, 100-102.

Gilmour, N. J. L. (1980). .Pasteurella haemolytica infections in sheep. Vet Q 2, 191-198.

Gilmour, N. J. L. \& Gilmour, J. S. (1989). Pasteurellosis of sheep. In Pasteurella and Pasteurellosis, pp. 223-261. Edited by C. F. Adlam \& J. M. Rutter. London: Academic Press.

Gilmour, N. J. L., Thompson, D. A. \& Fraser, J. (1974). The recovery of Pasteurella baemolytica from the tonsils of adult sheep. Res Vet Sci 17, 413-414.

Go, M. F., Kapur, V., Graham, D. Y. \& Musser, J. M. (1996). Population genetic analysis of Helicobacter pylori by multilocus enzyme electrophoresis: extensive allelic diversity and recombinational population structure. J Bacteriol 178, 3934-3938.

Haubek, D., Poulsen, K., Asikainen, S. \& Kilian, M. (1995). Evidence for absence in northern Europe of especially virulent clonal types of Actinobacillus actinomycetemcomitans. J Clin Microbiol 33, 395-401.

Lacroix, R. P., Duncan, J. R., Jenkins, R. P., Leitch, R. A., Perry, J. A. \& Richards, J. C. (1993). Structural and serological specificities of Pasteurella haemolytica lipopolysaccharides. Infect Immun 61, 170-181.

Lee, C. W., Lo, R. Y. C., Shewen, P. E. \& Mellors, A. (1994). The detection of the sialoglycoprotease gene and assay for sialoglycoprotease activity among isolates of Pasteurella haemolytica A1 strains, serotypes A13, A14, T15 and A16. FEMS Microbiol Lett 121, 199-206.

Leitch, R. A. \& Richards, J. C. (1988). Structure of the O-chain of the lipopolysaccharide of Pasteurella haemolytica serotype T3. Biochem Cell Biol 66, 1055-1065.

Maynard-Smith, J., Smith, N. H., O'Rourke, M. \& Spratt, B. G. (1993). How clonal are bacteria? Proc Natl Acad Sci USA 90, $4384-4388$.

Møller, K., Nielsen, R., Anderson, L. V. \& Kilian, M. (1992). Clonal analysis of the Actinobacillus pleuropneumoniae population in a geographocally restricted area by multilocus enzyme electrophoresis. J Clin Microbiol 30, 623-627.

Musser, J. M. \& Selander, R. K. (1990). Genetic analysis of natural populations of Staphylococcus aureus. In Molecular Biology of the Staphylococci, pp. 59-67. Edited by R. Novick \& R. A. Skurray. New York: VCH.

Musser, J. M., Hewlett, E. L., Peppler, M. S. \& Selander, R. K. (1986). Genetic diversity and relationships in populations of Bordetella spp. J Bacteriol 166, 230-237.

Musser, J. M., Rapp, V. J. \& Selander, R. K. (1987). Clonal diversity in Haemophilus pleuropneumoniae. Infect Immun 55, 1207-1215.

Musser, J. M., Kroll, J. S., Moxon, E. R. \& Selander, R. K. (1988a). Evolutionary genetics of the encapsulated strains of Haemophilus influenzae. Proc Natl Acad Sci USA 85, 7758-7762.

Musser, J. M., Kroll, J. S., Mowan, E. R. \& Selander, R. K. (1988b). Clonal population structure of encapsulated Haemophilus influenzae. Infect Immun 56, 1837-1845.

Mutters, R., Mannheim, W. \& Bisgaard, M. (1989). Taxonomy of the group. In Pasteurella and Pasteurellosis, pp. 3-34. Edited by C. F. Adlam \& J. M. Rutter. London: Academic Press.

Ochman, H. \& Selander, R. K. (1984). Evidence for clonal population structure in Escherichia coli. Proc Natl Acad Sci USA 81, 198-201.

Ørskov, F., Ørskov, I., Evans, D. J., Sack, R. B., Sack, D. A. \& Wadstrom, T. (1976). Special Escherichia coli serotypes among enterotoxigenic strains from diarrhoea in adults and children. Med Microbiol Immunol 162, 73-80.

Perry, M. B. \& Babiuk, L. A. (1984). Structure of the polysaccharide chain of Pasteurella haemolytica (serotype 4) lipopolysaccharide. Can J Biochem Cell Biol 62, 108-114.

Poulsen, K., Theilade, E., Lally, E. T., Demuth, D. R. \& Kilian, M. (1994). Population structure of Actinobacillus actinomycetemcomitans : a framework for studies of disease-associated properties. Microbiology 140, 2049-2060.

Richards, J. C. \& Leitch, R. A. (1989). Elucidation of the structure of the Pasteurella haemolytica serotype T10 lipopolysaccharide O-antigen by NMR spectroscopy. Carbohydr Res 186, 275-286.

Selander, R. K. \& Musser, J. M. (1990). Population genetics of bacterial pathogenesis. In The Bacteria, vol. 11, Molecular Basis of Bacterial Pathogenesis, pp. 11-36. Edited by B. H. Iglewski \& V. L. Clark. London: Academic Press.

Selander, R. K., Caugant, D. A., Ochman, H., Musser, J. M., Gilmour, M. N. \& Whittam, T. S. (1986). Methods of multilocus enzyme electrophoresis for bacterial population genetics and systematics. Appl Environ Microbiol 51, 873-884.

Smith, G. R. (1961). The characteristics of two types of Pasteurella 
haemolytica associated with different pathological conditions in sheep. J Pathol Bacteriol 81, 431-440.

Sneath, P. H. A. \& Sokal, R. R. (1973). In Numerical Taxonomy, p. 573. San Francisco: Freeman.

Sneath, P. H. A. \& Stevens, M. (1990). Actinobacillus rossii sp.nov., Actinobacillus seminis sp. nov., nom. rev., Pasteurella bettii sp. nov., Pasteurella lymphangitidis sp. nov., Pasteurella mairi sp. nov., and Pasteurella trehalosi sp. nov. Int J Syst Bacteriol 40, 148-153.

Received 12 February 1997; revised 7 March 1997; accepted 10 April 1997. 